Article

\title{
Overexpression of GmRIQ2-like (Glyma.04G174400) Enhances the Tolerance of Strong Light Stress and Reduces Photoinhibition in Soybean (Glycine max (L.) Merr.)
}

\author{
Jing Deng ${ }^{\dagger}$, Dongmei $\mathrm{Li}^{\dagger}{ }^{\dagger}$, Huayi Yin, Li Ma, Jiukun Zhang and Binbin Zhang * \\ Key Laboratory of Soybean Biology in Chinese Education Ministry (Northeastern Key Laboratory of Soybean \\ Biology and Genetics \&Breeding in Chinese Ministry of Agriculture), Northeast Agricultural University, \\ Harbin 150030, China; 13199075975@163.com (J.D.); yy841056@163.com (D.L.); yhy9762@163.com (H.Y.); \\ mail2020mailbox@163.com (L.M.); zhang170301066@163.com (J.Z.) \\ * Correspondence: zhangbinbin@neau.edu.cn; Tel.: +86-186-4609-2893 \\ † These authors contributed equally to this work.
}

Received: 7 February 2020; Accepted: 7 March 2020; Published: 7 May 2020

\begin{abstract}
Soybean (Glycine max (L.) Merr.) is an important crop that serves as a source of edible oil and protein. However, little is known about its molecular mechanism of adaptation to extreme environmental conditions. Based on the Arabidopsis thaliana sequence database and Phytozome, a soybean gene that had a highly similar sequence to the reduced induction of the non-photochemical quenching2 (AtRIQ2) gene, GmRIQ2-like (accession NO.: Glyma.04G174400), was identified in this study. The gene structure analysis revealed that GmRIQ2-like encoded a transmembrane protein. Elements of the promoter analysis indicated that GmRIQ2-like participated in the photosynthesis and abiotic stress pathways. The subcellular localization results revealed that the protein encoded by GmRIQ2-like was located in chloroplasts. The quantitative real-time (qRT)-PCR results revealed that GmRIQ2-like-overexpression (OE) and -knock-out (KO) transgenic soybean seedlings were cultivated successfully. The relative chlorophyll ( $\mathrm{Chl}$ ) and zeaxanthin contents and $\mathrm{Chl}$ fluorescence kinetic parameters demonstrated that GmRIQ2-like dissipated excess light energy by enhancing the non-photochemical quenching (NPQ) and reduced plant photoinhibition. These results suggested that GmRIQ2-like was induced in response to strong light and depressed Chl production involved in soybean stress tolerance. These findings indicate that the transgenic seedlings of GmRIQ2-like could be used to enhance strong light stress tolerance and protect soybean plants from photoinhibition damage. This study will serve as a reference for studying crop photoprotection regulation mechanisms and benefits the research and development of new cultivars.
\end{abstract}

Keywords: soybean (Glycine max (L.) Merr.); NPQ; photoinhibition; bioinformatics; subcellular localization; qRT-PCR

\section{Introduction}

Plants absorb light energy through chloroplasts located in their photosynthetic organs [1], which is subsequently converted into stable chemical energy and stored in inorganic substances that are synthesized into organic substances, and oxygen is released [2,3]. Light energy is an indispensable factor for plant growth and development [4-7]. When light energy is insufficient, plants regulate their external structures to capture enough light energy necessary for growth and development $[8,9]$. When light energy is in excess, it is absorbed by plants and exceeds their utilization ability, which results in photoinhibition [10-12]. When photosynthesis is inhibited, photosynthetic efficiency and capacity 
are reduced, and excess light energy that cannot be dissipated accumulates in the photosystem, thereby forming active oxygen [13-15], and causing photooxidation and photodamage in serious cases, which eventually leads to plant death [16-18].

Photoinhibition is a common phenomenon in nature [3]. When strong light simultaneously occurs with drought, heat, cold, salinity, nutrient deficiency or other stressors, photoinhibition is exacerbated [19-24]. A previous study demonstrated that drought stress induced the regulatory energy dissipation quantum yield of Kobresia alpinensis and Populus euphratica as light intensity increased, resulting in increased photoinhibition [25]. Soybean (Glycine max (L.) Merr.) is a main oil grain crop that often suffers from a variety of abiotic stressors [26]; thus, the degree of photoinhibition in this crop is relatively serious [27]. However, over their evolutionary histories, plants have formed a variety of defense mechanisms to protect their photosynthetic organs [28-30], including chloroplasts that avoid light movement, heat dissipation, active oxygen removal, and transition of the photosystem [6,31-33].

Nevertheless, superfluous photons that exceed the plant's capacity could be deleterious [34]. Moreover, redundant light energy leads to the inhibition of photosynthetic carbon fixation [35-37]. Under light stress, as the chlorophyll (Chl) content and oxygen evolution capacity decrease, the thylakoid structure is damaged $[27,38]$. Excess excitation energy produced by strong light reduces photosynthetic electron transfer, which combines with oxygen to form active oxygen $[9,39]$. Active oxygen destroys photosynthetic organs and reaction centers (RCs), resulting in reduced net photosynthetic rates and photochemical efficiency of Photosystem II (PS II) [40]. The reduction of the photosynthetic efficiency of PS II results in photoinhibition [41]. Under high light intensity, excess light energy that was absorbed is dissipated as heat [42].

RIQ proteins link the grana structure and organize light-harvesting complex II proteins (LHC IIs) [42], which play important roles in grana biogenesis [43-46]. PS II is located in thylakoid membranes of the chloroplasts in land plants, which mainly contain RCs, Chl $a / b$ LHC IIs, and an oxygen-evolving complex (OEC) $[47,48]$. Excessive Chl contents in the leaves make plants more sensitive to photoinhibition [49]. High light intensity stimulates the protection mechanism of plants, leading to higher non-photochemical quenching (NPQ) coefficients [50]. Higher NPQ induction levels and lower $\mathrm{Chl}$ contents balance the absorption of light energy under strong light conditions, thereby enhancing the adaptability of leaves in strong light environments [51]. Therefore, regulating the expression of proteins encoded by RIQ may provide a new method for improving the ability of plants to withstand environmental stressors.

In this study, a strong light-induced GmRIQ2-like gene was isolated from soybeans to stabilize the genetic overexpression $(\mathrm{OE})$ and knockout $(\mathrm{KO})$ of transgenic soybean seedlings as materials, and we explored the role of NPQ in light energy absorption to identify potential regulatory networks under light stress conditions. This gene effectively led to transgenic soybean plants that avoided photoinhibition and photodamage, providing experimental evidence for the improvement of soybean resistance to strong light stress. These findings will serve as a useful reference for the breeding of soybeans resistant to stress.

\section{Materials and Methods}

\subsection{Bioinformatics Analysis}

The AtRIQ2 protein sequence was obtained from TAIR [52]. Soybean DNA, mRNA, coding regions (CDS), and protein sequences of GmRIQ2-like were BLASTed using AtRIQ2 in Phytozome [53]. The physicochemical properties of GmRIQ2-like were observed using ExPasy [54]. TMHMM [55] was used to analyze the transmembrane. Promoter elements were analyzed using PlantCARE [56]. Phylogenetic analyses were conducted using MEGA5.0 (The Biodesign Institute, Tempe, AZ, USA). The correlated sequences of various species were acquired using BLASTp in the NCBI database [57] with the protein sequence encoded by GmRIQ2-like. The CRISPR/cas9 target sites of GmRIQ2-like were predicted using CRISPRdirect [58]. 


\subsection{Plant Materials, Growth Conditions, and RNA Isolation}

Soybean seeds of the "KenFeng 16" and "DongNong 50" cultivars were provided by the Soybean Research Institute of Northeast Agricultural University (Harbin, China). "KF16" seedlings were grown in soil:vermiculite (1:1) for 3 weeks under a $16 / 8 \mathrm{~h}$ light/dark photoperiod at $23^{\circ} \mathrm{C}$. The second stage of fully expanded trifoliate leaves was harvested and stored at $80^{\circ} \mathrm{C}$ for RNA isolation. Total RNA was extracted from "KF16" seedlings using a Trizol kit (TAKARA, Shiga, Japan) following the manufacturer's instructions. First-strand cDNA was synthesized using first-strand cDNA synthesis (Tiangen, Beijing, China) for PCR amplification.

\subsection{Construction of Related Vectors}

Full-length CDS of GmRIQ2-like was amplified using PrimeSTAR GXL DNA polymerase (TAKARA, Shiga, Japan). The PCR amplification procedure was as follows: $94{ }^{\circ} \mathrm{C}$ for $5 \mathrm{~min} ; 94^{\circ} \mathrm{C}$ for $30 \mathrm{~s}, 55^{\circ} \mathrm{C}$ for $30 \mathrm{~s}$, and 35 cycles at $72{ }^{\circ} \mathrm{C}$ for $30 \mathrm{~s}$; and $72{ }^{\circ} \mathrm{C}$ for $10 \mathrm{~min}$. The PCR products were cloned into the pGM-T vector (Tiangen, Beijing, China). Afterward, the ligation products were transformed into E. coli competence trans-T1 (Tiangen, Beijing, China). Single colonies were sequenced by Sangon Biotech (Beijing, China). Single enzyme cutting of the OE vector, pCXSN-bar, was conducted following the methods described by Li et al. [59] and performed by XcmI. Ligation between the CDS of GmRIQ2-like and pCXSN-bar was performed using $\mathrm{T}_{4}$ ligase (Tiangen, Beijing, China). Finally, the GmRIQ2-like-OE recombinant vector (GmRIQ2-a) was transformed into Agrobacterium tumefactions EHA105 using the freeze-thawing method [60]. The primers used for PCR of GmRIQ2-like cloning are provided (Table 1).

Table 1. List of primers used in this study.

\begin{tabular}{|c|c|}
\hline Primers & Primer Sequences $\left(5^{\prime}-3^{\prime}\right)$ \\
\hline GmRIQ2-like-OE-S & 5'-GCAACCTCGTCCCAACAAC-3' \\
\hline GmRIQ2-like-OE-A & 5'-CACCACCGAACCACCCATT-3' \\
\hline GmRIQ2-like-qRT-S & 5'-CCATTGTGCTCATTCCCG-3' \\
\hline GmRIQ2-like-qRT-A & $5^{\prime}$-ACCACTTCGCAACCATCT-3' \\
\hline Actin4-S & 5'-GTGTCAGCCATACTGTCCCCATT-3' \\
\hline Actin4-A & 5'-GTTTCAAGCTCTTGCTCGTAATCA-3' \\
\hline GmRIQ2-like-GFP-S & 5'-ATGGCGGTCCCTGCTACATCCTCA-3' \\
\hline GmRIQ2-like-GFP-A & 5'-GCAAGCCGCCGAGCACGAC-3' \\
\hline T7-gRNA-FPg & 5'-TAATACGACTCACTATAGGAGAAGGAGTGATTGGTGGTTTTAGTACTCTGGAAACAG-3' \\
\hline gRNA-RP & 5'-ATCTCGCCAACAAGTTGACGAG-3' \\
\hline CRISPR-GmRIQ2-like-S & $5^{\prime}$-TTGGAGAAGGAGTGATTGGTG-3' \\
\hline CRISPR-GmRIQ2-like-A & 5'-AАССАССААТСАСТССТТСТС-3' \\
\hline CRISPR-seq-A & 5'-CTCCTTCCTTCCGTCCACTTCATC-3' \\
\hline
\end{tabular}

Bgl II and Spe I double enzyme digestion (TAKARA, Shiga, Japan) of pCAMBIA1302 was employed for the Arabidopsis protoplast fluorescent localization expression vector. The cloning and connection processes are described above. The primers used for PCR of fluorescence localization are provided (Table 1).

The gene KO target site efficiency detection and CRISPR/cas9 vector construction of GmRIQ2-like were performed using a saCas9-gRNA target site efficiency detection kit (Viewsolid Biotech, Beijing, China) and a Plant Cas9/gRNA plasmid construction kit (Viewsolid Biotech, Beijing, China) following the manufacturer's instructions. By predicting the target sites of GmRIQ2-like exons, three sites were identified: GAGAAGGAGTGATTGGTGCGG, CCATGGCGAAGACGGTTAGGG, and AGAAGGAGTGGTTTGGAG. The activity of the GAGAAGGAGTGATTGGTGCGG target sites comprised up to $85 \%$ of the total according to the enzyme digestion assay and was selected for CRISPR/cas9 vector construction. The primers used for the CRISPR/cas9 technique are provided (Table 1). 


\subsection{Subcellular Localization in Arabidopsis Protoplasts}

GmRIQ2-like-GFP plasmids were used for transient assays via the polyethylene glycol transfection of Arabidopsis protoplasts, as described by Yoo et al. [61]. Transfected cells were imaged using a TCS SP2 confocal spectral microscope imaging system (Leica, Wetzlar, Germany).

\subsection{Cultivation of Transgenic Soybeans}

The transformation of transgenic A. tumefaciens into 'DN50' cotyledon nodes was conducted following the methods described by Jia et al. [62] with minor modifications. The reagents used for transformation are provided (Table 2). 'DN50' seeds were sterilized using chlorine and placed on germination medium (GM). A. tumefaciens $(50 \mu \mathrm{L})$ expressing the vectors GmRIQ2-a or GmRIQ2-b was added to $50 \mathrm{~mL}$ YEP liquid. The solutions were centrifuged for $10 \mathrm{~min}$ at $4000 \mathrm{rpm}$ until the OD value was $0.6-0.8$. Then, the scratched cotyledons were placed on transfection medium (LCCM) for $3 \mathrm{~d}$. Afterward, the cotyledons were recovered on shoot-induced medium $\left(\mathrm{SCCM}^{-}\right)$for $7 \mathrm{~d}$. Then, the cotyledons were filtered on selected medium $\left(\mathrm{SCCM}^{+}\right)$with $5 \mathrm{mg} / \mathrm{L}$ phosphinothricin (PPT) for $7 \mathrm{~d}$. Resistant cluster buds were placed in elongated medium (SEM) for 15-20 d until the buds were $3-4 \mathrm{~cm}$ long. Buds were cut and transferred to root media (RM) when the main roots were $3-5 \mathrm{~cm}$ long. Finally, seedlings were transplanted into soil:vermiculite (3:1) under a 16/8 h light/dark photoperiod at $23^{\circ} \mathrm{C}$ until the seedlings were mature.

Table 2. Media used for soybean cotyledonary explant transformation.

\begin{tabular}{|c|c|c|}
\hline Solution & $\mathrm{pH}$ & Composition (g/L) \\
\hline GM & 5.8 & B5: $3.21 \mathrm{~g}$; Sucrose: $20 \mathrm{~g}$; Agar: $7 \mathrm{~g}$; 6-BA: $1 \mathrm{mg} / \mathrm{L}$ \\
\hline LCCM & 5.4 & $\begin{array}{l}\text { B5: } 0.321 \mathrm{~g} \text {; Sucrose: } 30 \mathrm{~g} \text {; Mes: } 3.9 \mathrm{~g} \text {; Acetosyringone (As): } \\
160 \mathrm{mg} / \mathrm{L} \text {;Gibberellic acid (GA): } 10 \mathrm{mg} / \mathrm{L} ; 6-\mathrm{BA}: 1 \mathrm{mg} / \mathrm{L}\end{array}$ \\
\hline SCCM & 5.4 & $\begin{array}{l}\text { B5: } 0.321 \text { g; Sucrose: } 30 \text { g; Mes: } 3.9 \text { g; Agar: } 5 \text { g; As: } 160 \text { mg/L; GA: } \\
10 \text { mg/L;BA: } 1 \text { mg/L; DTT: } 0.154 \text { g; L-cysteine: } 1 \text { g; } \mathrm{Na}_{2} \mathrm{~S}_{2} \mathrm{O}_{3}: 0.248 \mathrm{~g}\end{array}$ \\
\hline $\mathrm{SSIM}^{-}$ & 5.6 & $\begin{array}{c}\text { B5: } 3.21 \text { g; Sucrose: } 30 \text { g; Mes: } 0.59 \text { g; Agar: } 7.5 \text { g; 6-BA: } 1 \mathrm{mg} / \mathrm{L} ; \\
\text { Cefotaxime (cef): } 250 \mathrm{mg} / \mathrm{L}\end{array}$ \\
\hline $\operatorname{SSIM}^{+}$ & 5.6 & $\begin{array}{l}\text { B5: } 3.21 \text { g; Sucrose: } 30 \text { g; Mes: } 0.59 \text { g; Agar: } 7.5 \text { g; 6-BA: } \\
1 \text { mg/L;Phosphinothricin (PPT): } 5 \text { mg/L; cef: } 250 \text { mg/L }\end{array}$ \\
\hline SEM & 5.6 & $\begin{array}{c}\text { Murashige and Skoog (MS): } 4.43 \text { g; Sucrose: } 30 \text { g; Mes: } 0.59 \text { g; Agar: } \\
\text { 7.5 g;Aspirin (Asp): } 50 \mathrm{mg} / \mathrm{L} ; \mathrm{N} \text {,6-isopentenyladenine (ZR): } 1 \mathrm{mg} / \mathrm{L} ; \\
\text { Gibberellin }\left(\mathrm{GA}_{3}\right): 1 \mathrm{mg} / \mathrm{LIndole-3-acetic} \mathrm{acid} \mathrm{(IAA):} 1 \mathrm{mg} / \mathrm{L} \text {; cef: } \\
250 \mathrm{mg} / \mathrm{L}\end{array}$ \\
\hline $\mathrm{RM}$ & 5.6 & $\begin{array}{c}\text { B5: } 3.21 \text { g; Sucrose: } 20 \text { g; Mes: } 0.59 \text { g; Agar: } 7.0 \mathrm{~g} \text {; Indole-3-butytric } \\
\text { acid (IBA): } 1 \mathrm{mg} / \mathrm{mL}\end{array}$ \\
\hline
\end{tabular}

Annotate: Germination medium (GM); Transfection medium (LCCM); Shoot-induced medium (SCCM ${ }^{-}$); Selected medium $\left(\mathrm{SCCM}^{+}\right)$; Elongated medium (SEM); Root media (RM).

\subsection{Detection of Transgenic Soybeans Using Quantitative Real-Time PCR}

Total RNA was isolated from transgenic and wild-type (WT) soybean leaves using TRIzol reagent (TAKARA, Shiga, Japan). First-strand cDNA synthesis was performed as described above. Quantitative real-time (qRT)-PCR was performed on a Chromo4 RT-PCR system (Bio-Rad, Hercules, CA, USA) using SYBR Green PCR Master mix (Tiangen, Beijing, China). The soybean actin4 gene was used as an internal standard control. The primers used for qRT-PCR are provided (Table 3). The PCR procedure was as follows: $95^{\circ} \mathrm{C}$ for $5 \mathrm{~min} ; 95^{\circ} \mathrm{C}$ for $30 \mathrm{~s}, 60^{\circ} \mathrm{C}$ for $30 \mathrm{~s}$, and 40 cycles at $72{ }^{\circ} \mathrm{C}$ for $30 \mathrm{~s}$; and $72{ }^{\circ} \mathrm{C}$ for $10 \mathrm{~min}$. After qRT-PCR was conducted, the relative mRNA ratios were calculated using the $2^{-\Delta \Delta C T}$ method. All PCR experiments were conducted three times using prepared $T_{2}$ and $T_{3}$ generation homozygous independent cDNA. GmRIQ2-like-OE and -KO transgenic soybean seedlings identified as positive were named GmRIQ2-a1,a2,a3 and GmRIQ2-b1,b2,b3. 
Table 3. Promoter elements of GmRIQ2-like.

\begin{tabular}{ccc}
\hline Name & Number & Function \\
\hline G-Box & 8 & \\
box-4 & 5 & \\
box II & 2 & \\
ATCT-motif & 1 & \\
CATT-motif & 1 & \\
CG-motif & 1 & \\
ACE & 1 & \\
GATA-motif & 1 & \\
I-box & 1 & \\
ABRE & 5 & involved in abscisic acid responsiveness \\
HSE & 3 & involved in heat stress responsiveness \\
TCA-element & 2 & involved in salicylic acid responsiveness \\
AuxRR-core & 1 & involved in auxin responsiveness \\
TC-rich repeats & 1 & involved in defense and stress responsiveness \\
circadian & 1 & involved in circadian control \\
ARE & 1 & essential for anaerobic induction \\
\hline
\end{tabular}

\subsection{Measurements of Physiological Characteristics in Transgenic Agronomic Traits}

Soil-plant analyses development (SPAD) values were employed for detecting the relative Chl contents of transgenic soybean seedling leaves using a SPAD-502 Chl meter (Konica Minolta, Tokyo, Japan). First, the light intensity reading of $\mathrm{A}_{650}$ and $\mathrm{A}_{940}$ was recorded under non-blade conditions. After the blades were inserted, light intensity was read at the two wavelengths again. Finally, SPAD values were calculated using the following formula: SPAD $=\mathrm{Klg}(\mathrm{IRt} / \mathrm{IR} 0) /(\mathrm{Rt} / \mathrm{R} 0)$, where $\mathrm{K}$ is a constant, IRt is the infrared intensity of leaves under $940 \mathrm{~nm}$, IR0 is the infrared intensity of non-blade parts under $940 \mathrm{~nm}$, Rt is the infrared intensity of leaves under $650 \mathrm{~nm}$, and R0 is the infrared intensity of non-blade parts under $650 \mathrm{~nm}$.

The second stage of fully expanded trifoliate leaves was harvested and stored at $-80{ }^{\circ} \mathrm{C}$ for zeaxanthin extraction. Then, the leaves were ground into a homogenate with $80 \%$ acetone and centrifuged at $200 \mathrm{~g}$ for $5 \mathrm{~min}$. Finally, using $80 \%$ acetone as a reference, the light absorption of the liquid supernatant was detected at 505 and $652 \mathrm{~nm}$ (the light absorptions of $\mathrm{Chl}$ ). Because the diurnal variation of the $\mathrm{Chl}$ contents was not obvious, the $A_{505} / A_{652}$ values were used to express the relative zeaxanthin contents of transgenic and WT soybean leaves.

Agronomic traits, including the plant height and number of main nodes, pods, and seeds of transgenic and WT plants, were measured based on grain physiological maturity dates. Transgenic and WT plants were grown in soil:vermiculite (1:1) pots under a $16 / 8 \mathrm{~h} \mathrm{light/dark} \mathrm{photoperiod} \mathrm{at} 23^{\circ} \mathrm{C}$. The light intensity was maintained at about $500 \mu \mathrm{mol} \mathrm{m}{ }^{-2} \cdot \mathrm{s}^{-1}$ during the measurement.

\subsection{Determination of Chl Fluorescence Kinetic Parameters}

The Chl fluorescence kinetic parameters of the third fully expanded trifoliate leaves of the $\mathrm{T}_{2}$ and $\mathrm{T}_{3}$ generation transgenic 'DN50' control plants were measured using a Li-6400XT portable photosynthesis analyzer (Li-Cor, Lincoln, NE, USA). Leaves were dark-adapted for $30 \mathrm{~min}$, and the initial fluorescence (Fo) under dark adaptation was measured with weakly-modulated measuring light. Then, a saturated flash $\left(8000 \mu \mathrm{mol} \mathrm{m}{ }^{-2} \cdot \mathrm{s}^{-1}, 0.8 \mathrm{~s}\right.$ pulse time) was used to determine the maximum fluorescence $(\mathrm{Fm})$ followed by continuous light activation $\left(1000 \mu \mathrm{mol} \mathrm{m}{ }^{-2} \cdot \mathrm{s}^{-1}\right)$ to irradiate the leaves in order to reach steady-state fluorescence (Fs). Afterward, a saturated flash $\left(8000 \mu \mathrm{mol} \mathrm{m}^{-2} \mathrm{~s}^{-1}, 0.8 \mathrm{~s}\right.$ pulse time) was used to determine the maximum fluorescence $\left(\mathrm{Fm}^{\prime}\right)$ under light adaptation. Finally, the photochemical light was turned off, and far-red light was turned on for $3 \mathrm{~s}$ to measure the minimum fluorescence (Fo') under light adaptation. The Fo, Fm, and PS II maximum photochemical efficiency (Fv/Fm), and $\mathrm{NPQ}$, were obtained by recording measurements and calculations under 500 and $1800 \mu \mathrm{mol} \mathrm{m} \mathrm{m}^{-2} \cdot \mathrm{s}^{-1}$ 
light intensity. Each treatment was repeated three times. For determination of the fluorescence kinetic parameters, refer to Li and Tao $[63,64]$. The parameters were calculated as follows: NPQ = Fm/Fm'-1. After testing, one of the third trifoliate leaves of the corresponding test leaf was retrieved, and the $\mathrm{Chl}$ fluorescence quenching process was measured indoors. After leaves were dark-adapted for $30 \mathrm{~min}$, they were placed in a Chl fluorescence imager (IMAG-MAX/L, Walz, Germany), the application was implemented, the fluorescence parameter values were measured, and the images were saved.

\subsection{Statistical Analyses}

All results were repeated three times. Data are presented as the mean \pm standard error (SE). The data were analyzed by Student's $t$ test using SPSS v17.0 (SPSS Inc., Chicago, IL, USA).

\section{Results}

\subsection{Gene Structure and Phylogenetic Analyses of GmRIQ2-like}

According to the AtRIQ2 protein sequence (TAIR: AT1G74730) in Arabidopsis thaliana, the full-length genomic sequence of Glyma.04G174400, named GmRIQ2-like in this study, was obtained using the BLAST tool in Phytozome (Figure 1A). The genomic, transcription, and CDS regions of GmRIQ2-like contained 2482, 1243, and $585 \mathrm{bp}$, respectively. Two introns were located in the CDS and $3^{\prime}$ untranslated regions with lengths of 688 and 18 bp, respectively. Proteins encoded by GmRIQ2-like consisted of 194 amino acids with a theoretical isoelectric point (pI) of 9.10 and estimated molecular weight of 20,385.7 Da. Additionally, the transmembrane structure was identified in the protein encoded by GmRIQ2-like, indicating that GmRIQ2-like was a transmembrane protein. The promoter elements analysis revealed that GmRIQ2-like participated in photosynthesis and various abiotic stress responses (Table 3). Specifically, there were 21 elements related to light responsiveness, including 5 ABRE, 3 HSE, 2 TCA, 1 AuxRR-core, TC-rich repeats, and ARE elements, which are involved in abscisic acid, heat, salicylic acid, auxin, defense, and stress responses, as well as anaerobic induction. To evaluate the evolutionary relationships within the GmRIQ2-like family, a combined phylogenetic analysis was performed using 14 RIQ2 proteins (Figure 1B). The results indicated that GmRIQ2-like was highly homologous with Phaseolus vulgaris L.

\subsection{Subcellular Localization of GmRIQ2-like}

GmRIQ2-like was predicted to serve a function related to NPQ. A potential protein encoded by GmRIQ2-like was found to be located in the chloroplasts. Therefore, the GmRIQ2-like::GFP fusion protein vector was transferred into $A$. thaliana protoplasts with high concentrations of PEG4000. The control protoplast was not transferred to the vector. Observations using a confocal laser scanning microscope revealed that the green fluorescence of GmRIQ2-like::GFP was located in the chloroplasts, while the control protoplast exhibited no fluorescence (Figure 2). 


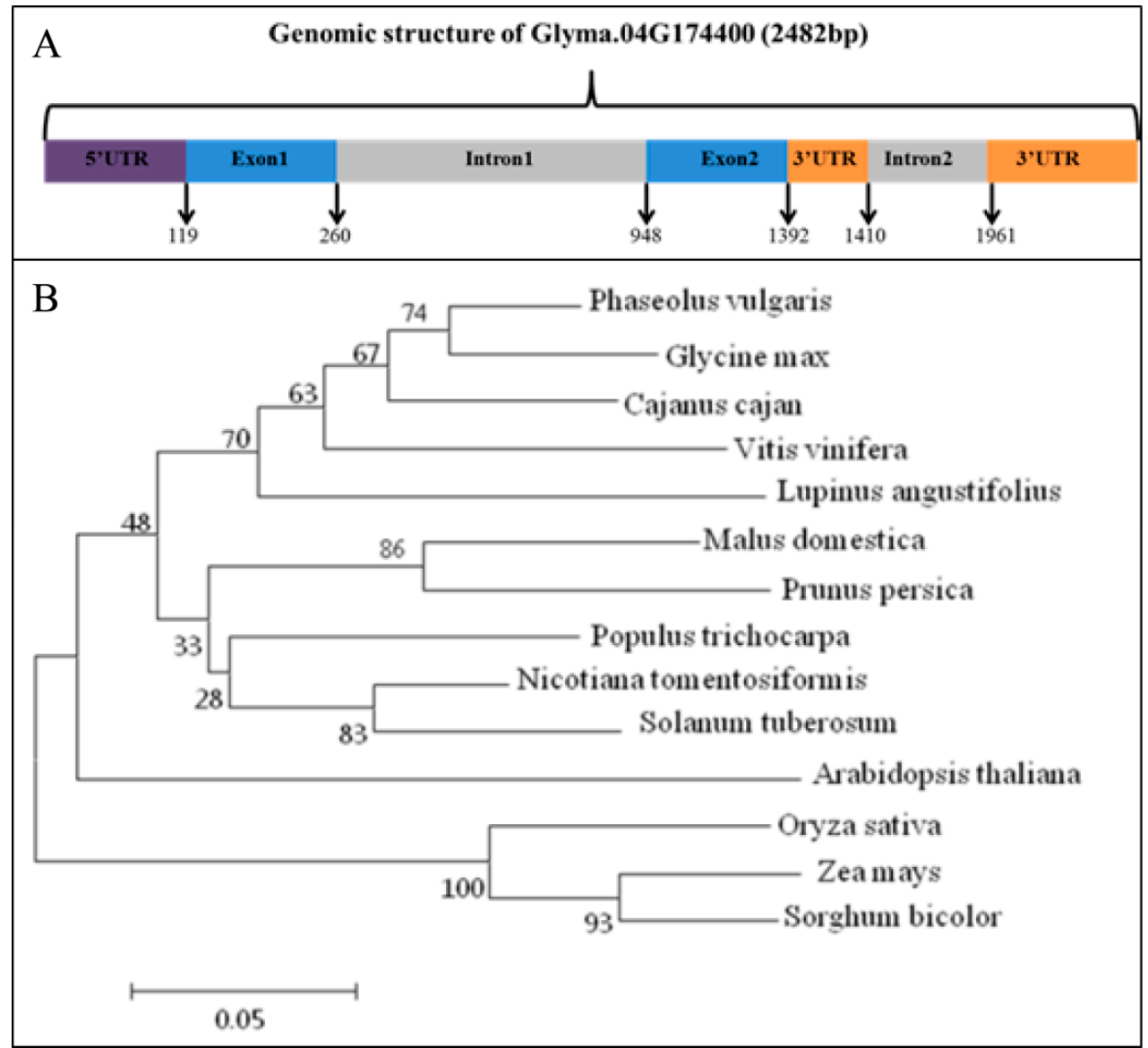

Figure 1. Bioinformatic analyses of GmRIQ2-like. (A) Genomic sequence structure of GmRIQ2-like. (B) Phylogenic analysis of GmRIQ2-like, which involved 14 amino acid sequences. In the phylogenetic tree, taxon names were replaced by the species name. Evolutionary analyses were conducted in MEGA5.0.

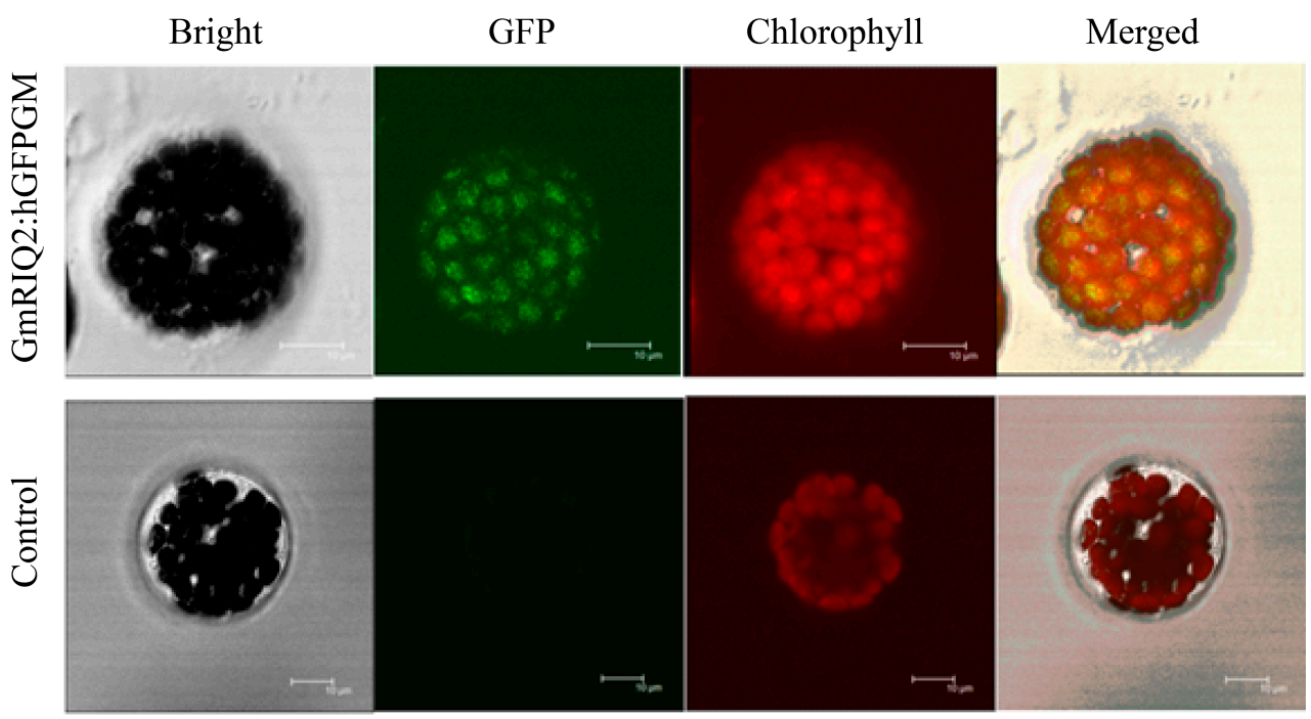

Figure 2. The subcellular localization of GmRIQ2-like was investigated in Arabidopsis protoplasts under a confocal microscope. The fluorescent distribution of control and fusion proteins of GmRIQ2-like-GFP were observed under white, UV, and red light. Bars $=10 \mu \mathrm{m}$. 


\subsection{Identification of GmRIQ2-like Transgenic Soybeans}

The GmRIQ2-like overexpression vector (GmRIQ2-a) and GmRIQ2-like knock-out vector (GmRIQ2-b) were constructed successfully from the cDNA of soybean cultivar 'KF16' and transferred into 'DN50' soybean cotyledons by the Agrobacterium tumefaciens-mediated method. After the $\mathrm{T}_{1}$ generation seeds of soybean were harvested, the quantitative real-time PCR (qRT-PCR) was used to detect positive transgenic seedlings (Figure 3). GmRIQ2-like-OE-transgenic soybean seedlings (a3) exhibited significantly higher expression levels, which were $14 \times$ higher than WT and greater than the other 6 detected seedlings (a1-a7) (Figure 3A). Additionally, seedlings a1 and a7 also exhibited various degrees of OE levels, which were 3.5 and $4 \times$ higher than WT (Figure 3A). The expression levels of GmRIQ2-like in all 6 detected KO transgenic soybean seedlings (b1-b6) were $\leq 1 / 5 \times$ lower than WT (Figure 3B). These results indicated that GmRIQ2-like-OE and -KO transgenic soybean seedlings were obtained successfully.
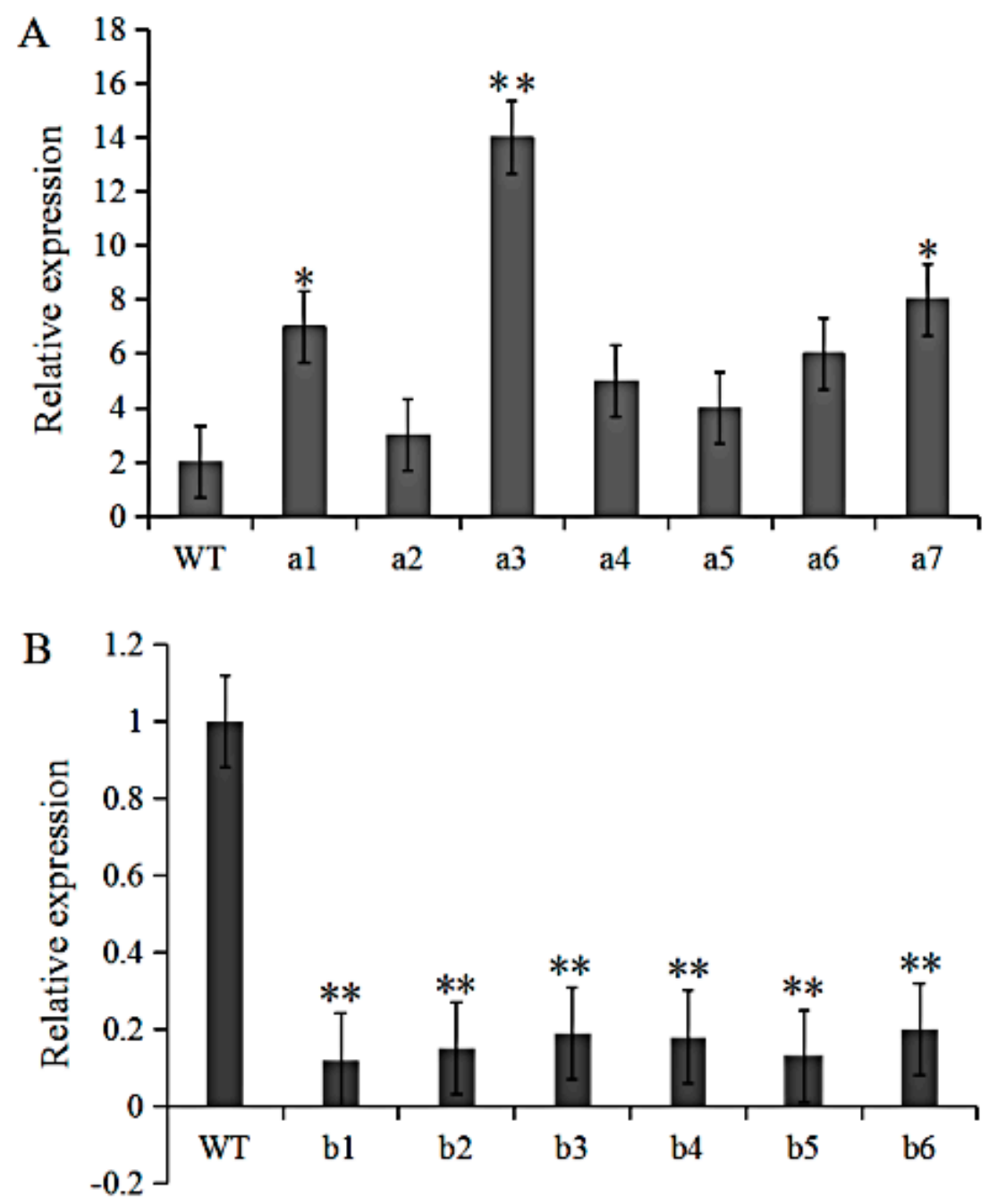

Figure 3. Identification of GmRIQ2-like-overexpression (OE) and -knock-out $(\mathrm{KO})$ transgenic soybean seedlings. (A) Expression patterns of the $\mathrm{T}_{0}$ generation of GmRIQ2-like-OE transgenic soybean seedlings (a1-a7). (B) Expression patterns of the $\mathrm{T}_{0}$ generation of GmRIQ2-like-KO transgenic soybean seedlings (b1-b6). Relative transcript levels were determined by qRT-PCR using the $2^{-\Delta \Delta C t}$ method; the actin4 gene was used as an internal control. Data are presented as the average of three independent biological experiments \pm SE. Asterisks indicate significant differences $\left({ }^{*} p<0.05 ;{ }^{* *} p<0.01\right)$ compared to the control. 


\subsection{Agronomic Traits and Physiological Indices of GmRIQ2-like Transgenic Seedlings}

The agronomic traits of the $\mathrm{T}_{2}$ generation of GmRIQ2-like-OE, -KO, and WT seedlings were measured (Table 4A). The plant height and number of nodes, pods, and seeds of the detected seedlings were ranked as follows: GmRIQ2-like-KO > WT > GmRIQ2-like-OE. Combined with the growth phenotypes (Figure 4A), these results indicated that the expression of GmRIQ2-like had a negative effect on soybean yield under the tested conditions.

Table 4. (A) Agronomic traits of the wild-type (WT) and $\mathrm{T}_{2}$ generation of GmRIQ2-like-OE and -KO transgenic seedlings. (B) Agronomic traits of the WT and $\mathrm{T}_{3}$ generation of GmRIQ2-like-OE and -KO transgenic seedlings.

\begin{tabular}{|c|c|c|c|}
\hline \multicolumn{4}{|c|}{ (A) } \\
\hline Agronomic Traits & WT & GmRIQ2-like-OE & GmRIQ2-like-KO \\
\hline Plant height $(\mathrm{cm})$ & $68.5 \pm 3.2$ & $64.8 \pm 2.4$ & $71.0 \pm 4.8$ \\
\hline Number of main nodes (no.) & $15 \pm 2$ & $15 \pm 1$ & $16 \pm 2$ \\
\hline Number of pods (no.) & $27 \pm 3$ & $26 \pm 2$ & $28 \pm 3$ \\
\hline Number of seeds (no.) & $71 \pm 4$ & $65 \pm 3$ & $74 \pm 5$ \\
\hline Weight of seed per plant (g) & $6.3 \pm 0.5$ & $5.3 \pm 0.4$ & $6.9 \pm 0.7$ \\
\hline Hundred-grain weight (g) & $8.9 \pm 0.2$ & $8.1 \pm 0.2$ & $9.3 \pm 0.3$ \\
\hline \multicolumn{4}{|c|}{ (B) } \\
\hline Agronomic Traits & WT & GmRIQ2-like-OE & GmRIQ2-like-KO \\
\hline Plant height $(\mathrm{cm})$ & $67.8 \pm 2.8$ & $62.7 \pm 2.5$ & $69.3 \pm 3.2$ \\
\hline Number of main nodes (no.) & $15 \pm 2$ & $14 \pm 2$ & $16 \pm 1$ \\
\hline Number of pods (no.) & $26 \pm 1$ & $25 \pm 2$ & $29 \pm 2$ \\
\hline Number of seeds (no.) & $68 \pm 3$ & $66 \pm 2$ & $73 \pm 4$ \\
\hline Weight of seed per plant (g) & $5.9 \pm 0.5$ & $5.5 \pm 0.3$ & $6.7 \pm 0.7$ \\
\hline Hundred-grain weight (g) & $8.7 \pm 0.3$ & $8.4 \pm 0.2$ & $9.2 \pm 0.4$ \\
\hline
\end{tabular}

A

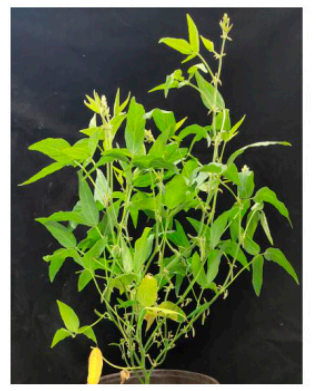

GmRIQ2-like-KO

B

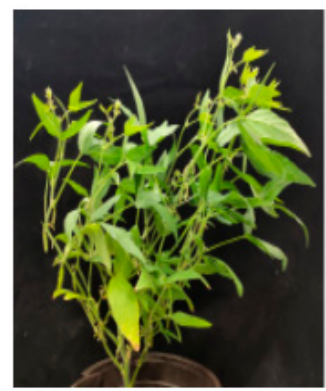

GmRIQ2-like-KO

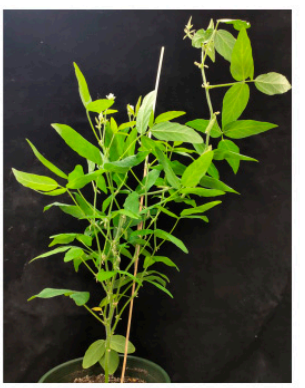

WT

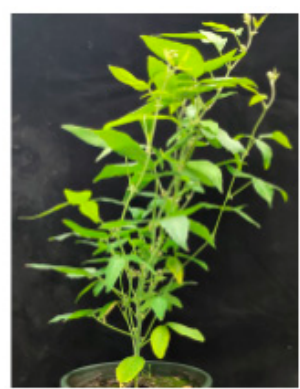

WT

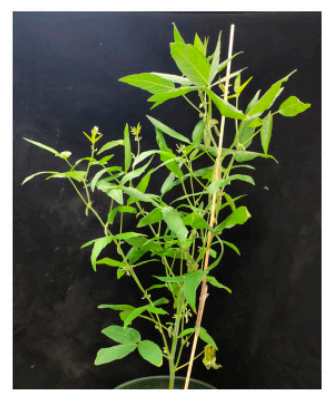

GmRIQ2-like-OE

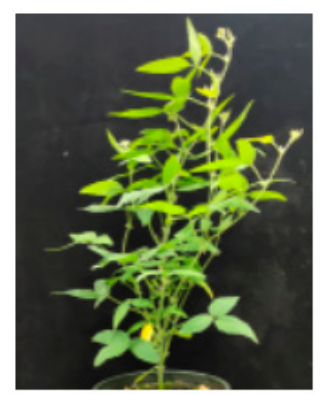

GmRIQ2-like-OE

Annotate: The plant with Dongnong 50 as a control was named wild-type (WT).

Figure 4. Phenotypes of two-month old GmRIQ2-like-KO, -OE, and WT transgenic soybean seedlings. (A) Phenotype of the $T_{2}$ generation of transgenic soybean seedlings. (B) Phenotype of the $T_{3}$ generation of transgenic soybean seedlings. For each strain, 30 seedlings were selected. 
Interestingly, under the tested light conditions, the SPAD values of the $\mathrm{T}_{2}$ generation of GmRIQ2-like-OE seedlings were lower than WT (Figure 5A). The $\mathrm{A}_{505} / \mathrm{A}_{652}$ values in the $\mathrm{T}_{2}$ generation leaves of GmRIQ2-like-OE, -KO, and WT seedlings were ranked as follows: GmRIQ2-like-OE > WT $>$ GmRIQ2-like-KO (Figure 5B). The SPAD values, $\mathrm{A}_{505} / \mathrm{A}_{652}$ values, and agronomic traits of the $\mathrm{T}_{3}$ generation of GmRIQ2-like-OE, -KO, and WT seedlings exhibited the same trends as the $\mathrm{T}_{2}$ generation (Table 4B; Figure 6). These results further suggested that GmRIQ2-like enhanced NPQ, reduced Chl synthesis, and ultimately had some impact on soybean yield.
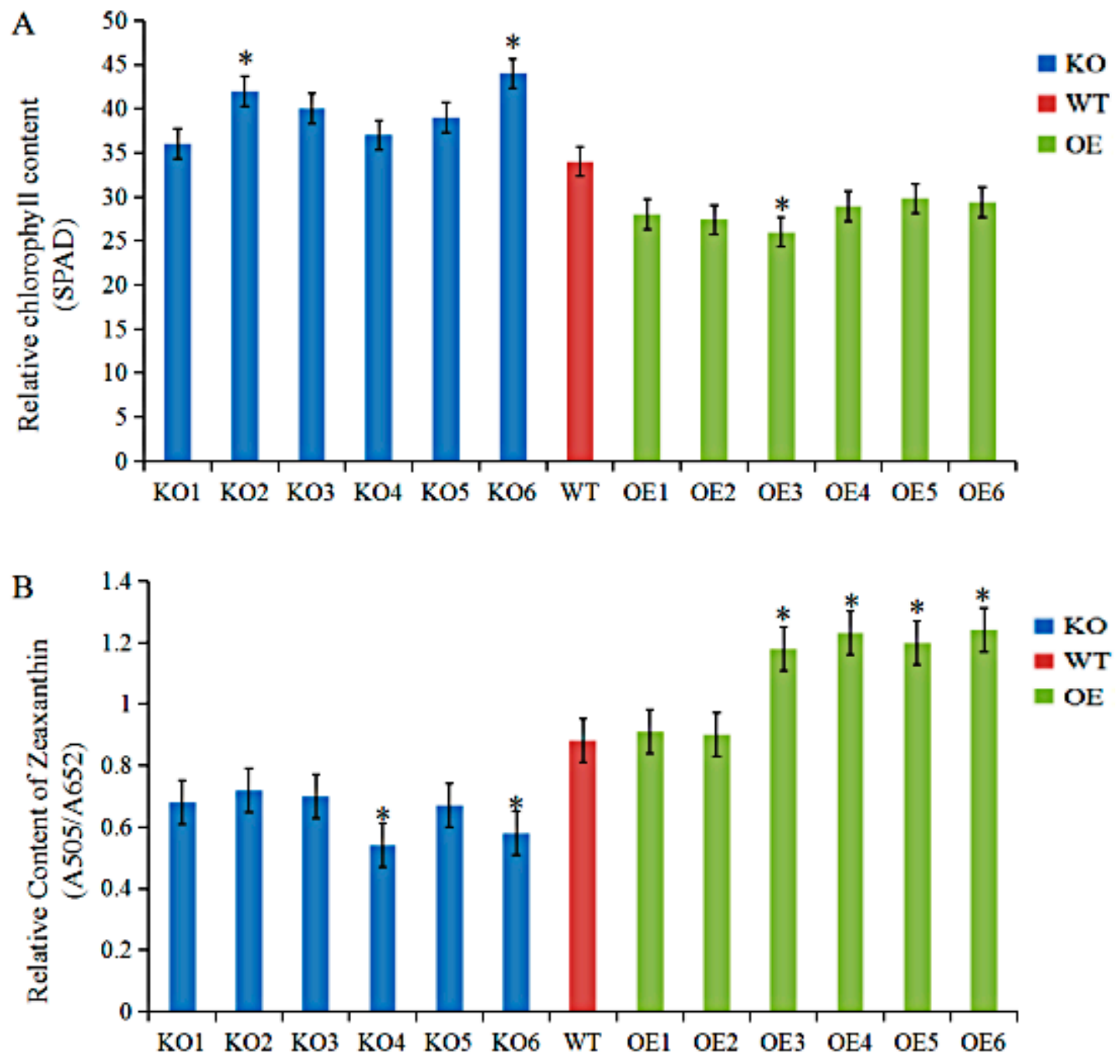

Figure 5. Non-photochemical quenching (NPQ)-related physiological indicators of WT and the $\mathrm{T}_{2}$ generation of GmRIQ2-like-OE and -KO transgenic one-month seedlings. (A) SPAD (soil-plant analyses development) values of WT and GmRIQ2-like-OE transgenic soybean seedlings were detected using a SPAD-502 Chl meter to obtain the relative contents of Chl. (B) The relative zeaxanthin contents of WT, GmRIQ2-like-OE, and -KO transgenic soybean seedlings were detected using a spectrophotometer at 505 and $652 \mathrm{~nm}$. Vertical bars represent the SE ( $n=3$; each treatment consisted of 30 seedlings). Asterisks indicate significant differences $\left({ }^{*} p<0.05\right)$ between the transgenic lines and WT. 

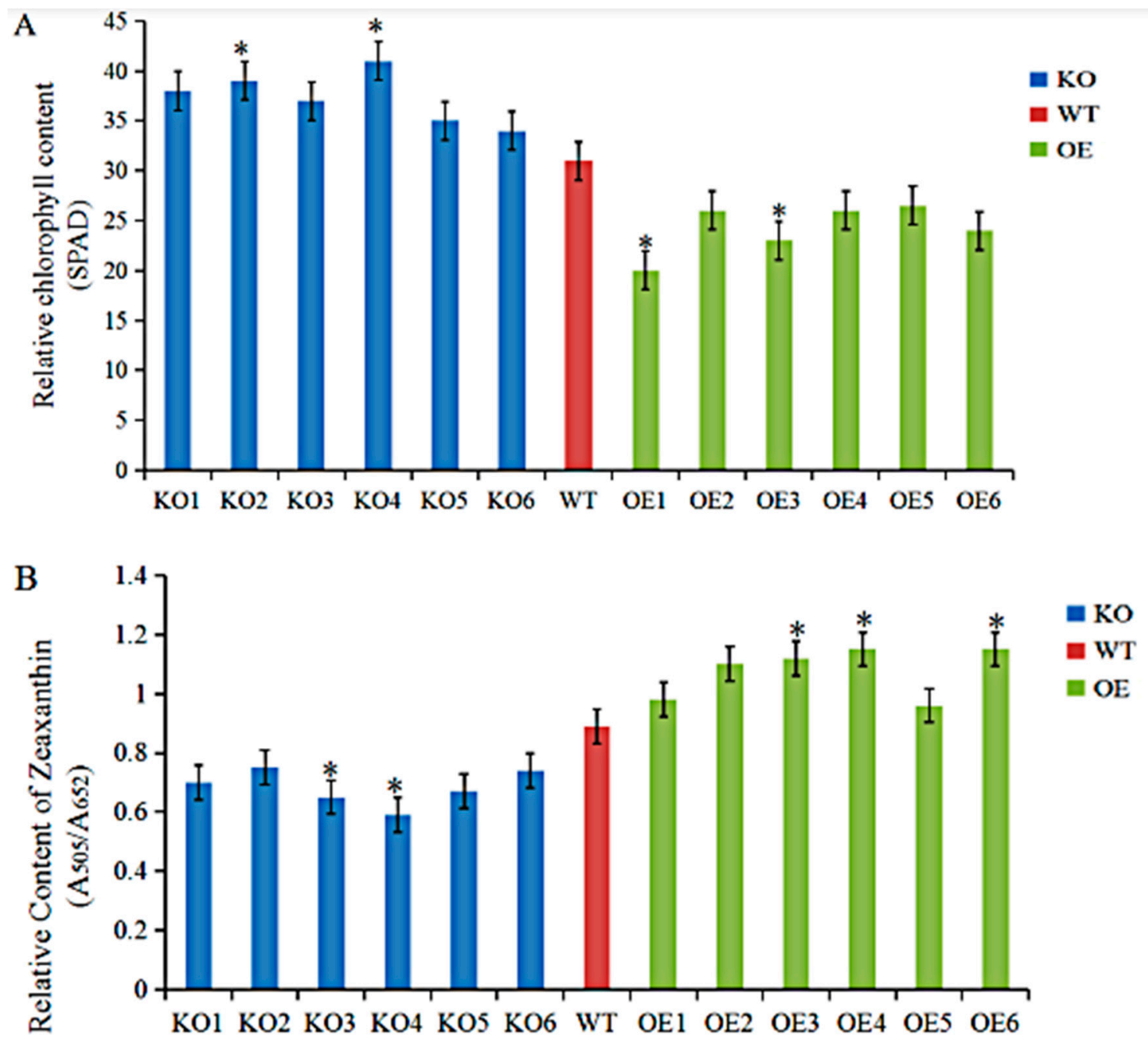

Figure 6. NPQ-related physiological indicators of WT and the $\mathrm{T}_{3}$ generation of GmRIQ2-like-OE and -KO transgenic one-month seedlings. (A) SPAD values of WT and GmRIQ2-like-OE transgenic soybean seedlings were detected using a SPAD-502 Chl meter to obtain the relative contents of Chl. (B) The relative zeaxanthin contents of WT, GmRIQ2-like-OE, and -KO transgenic soybean seedlings were detected using a spectrophotometer at 505 and $652 \mathrm{~nm}$. Vertical bars represent the SE ( $n=3$; each treatment consisted of 30 seedlings). Asterisks indicate significant differences $\left({ }^{*} p<0.05\right)$ between the transgenic lines and WT.

\subsection{Chl fluorescence Kinetic Parameters of the $T_{2}$ and $T_{3}$ Generations of GmRIQ2-like Transgenic Seedlings}

Changes in the Chl fluorescence parameters, $\mathrm{Fo}, \mathrm{Fm}, \mathrm{Fv} / \mathrm{Fm}$, and NPQ in the $\mathrm{T}_{2}$ and $\mathrm{T}_{3}$ generations of GmRIQ2-like-OE, -KO, and WT seedling leaves under different light intensities were measured (Figures 7 and 8). Fo represents the fluorescence yield of the PS II RC in the completely open state, and changes in its value infer the state of the RC. In the $\mathrm{T}_{2}$ generation of GmRIQ2-like-OE, -KO, and WT seedlings, Fo was ranked as follows: GmRIQ2-like-OE $<$ WT < GmRIQ2-like-KO (Figure 7A). These results indicated that the photosynthetic electron transport of the PS II RC in soybean leaves was blocked due to strong light stress, which resulted in damage to the PS II RC. Fv/Fm of the $\mathrm{T}_{2}$ generation of GmRIQ2-like-OE, $-\mathrm{KO}$, and WT seedlings was ranked as follows: GmRIQ2-like-OE > WT > GmRIQ2-like-KO (Figure 7B). Compared to GmRIQ2-like-KO and WT seedlings, GmRIQ2-like-OE seedlings exhibited a stronger heat dissipation ability under strong light stress. The gradual enhancement of light intensity led to a gradual increase of NPQ in the $T_{2}$ generation of GmRIQ2-like-OE, -KO, and WT seedlings, which were ranked as follows: GmRIQ2-like-OE > WT > 
GmRIQ2-like-KO (Figure 7C). These results further indicated that the electron transfer of PS II was inhibited, and this ability decreased due to strong light stress, which thereby led to a decrease in photosynthetic capacity. The heat dissipation of NPQ dissipated excess light energy and protected photosynthetic organs that were not destroyed by photoinhibition, which thereby alleviated the effects of strong light stress on photosynthesis. The NPQ of GmRIQ2-like-OE seedlings increased significantly, which improved their heat dissipation ability and strong light stress resistance, thereby alleviating photoinhibition and playing a role in photoprotection. When the $\mathrm{T}_{3}$ generation of GmRIQ2-like-OE, $-\mathrm{KO}$, and WT seedlings was resistant to strong light, changes in the trends of various parameters were roughly the same as the $T_{2}$ generation seedlings (Figure 8 ).
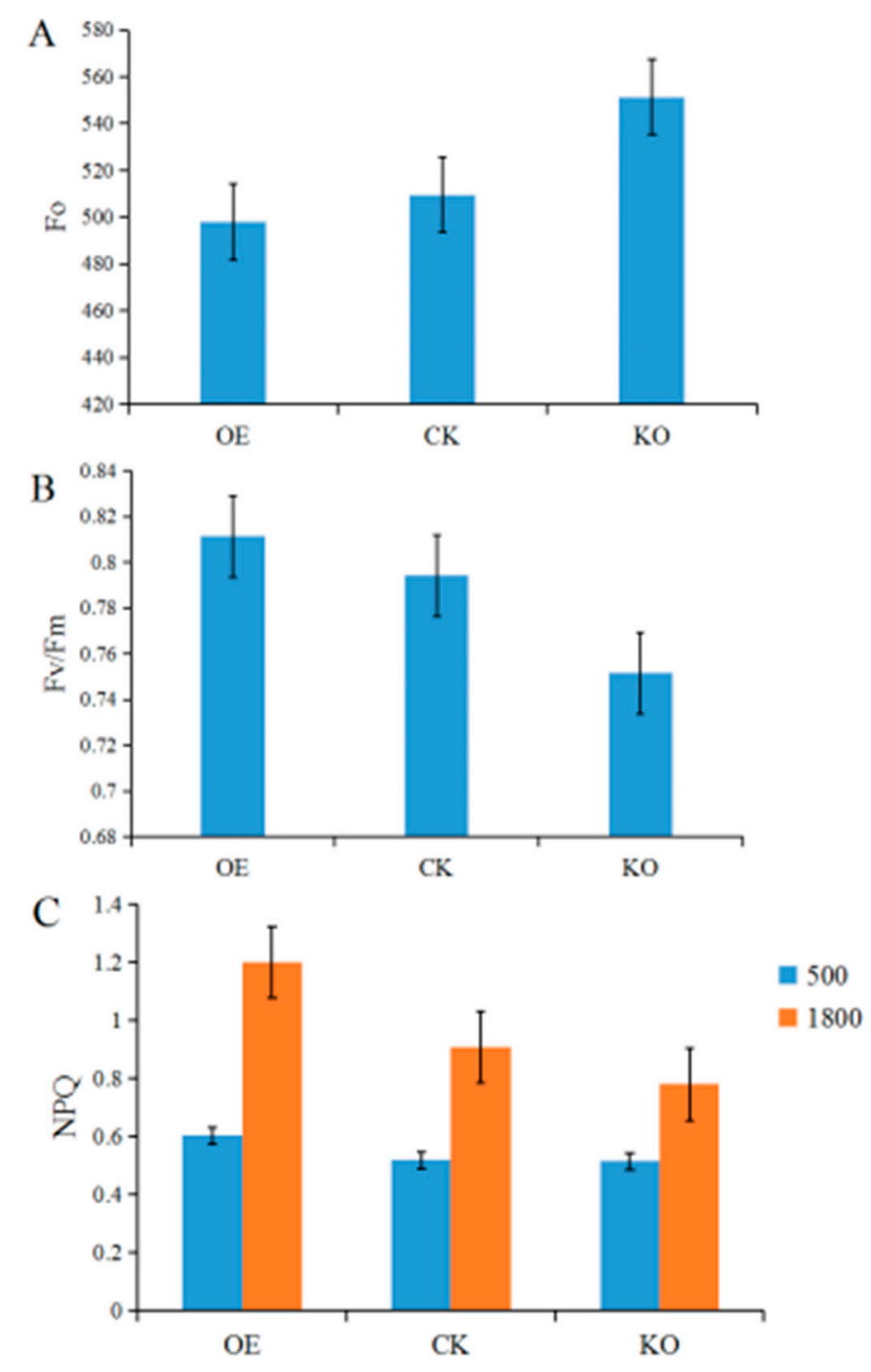

Figure 7. Chl fluorescence kinetic parameters of $\mathrm{WT}$ and the $\mathrm{T}_{2}$ generation of GmRIQ2-like-OE and -KO transgenic soybean seedlings. (A-C) represent the effects of different light intensities on the Fo, $\mathrm{Fv} / \mathrm{Fm}$, and NPQ of three types of soybean leaves. Vertical bars represent the SE $(n=3$; each treatment consisted of 30 seedlings). 

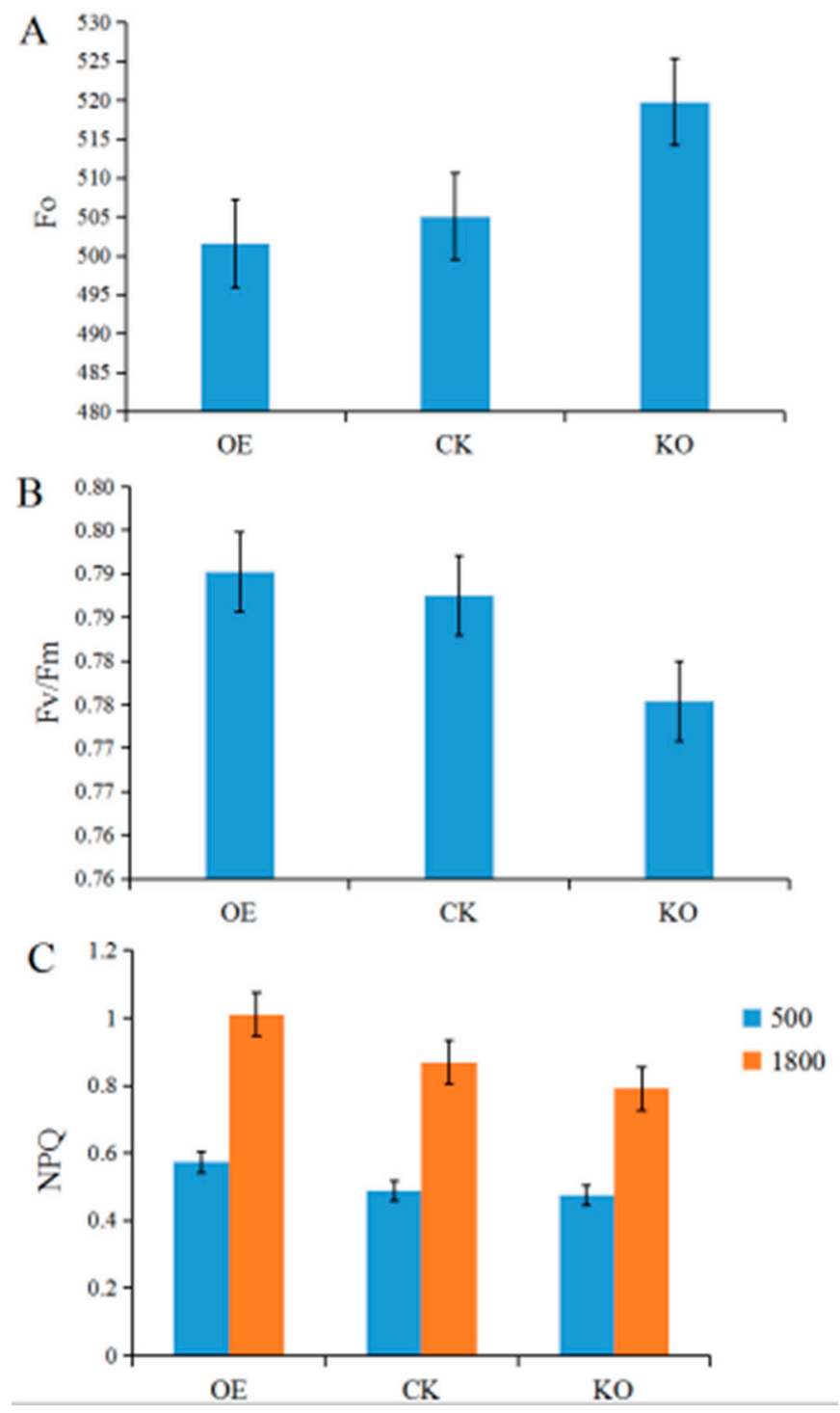

Figure 8. Chl fluorescence kinetic parameters of $\mathrm{WT}$ and the $\mathrm{T}_{3}$ generation of GmRIQ2-like-OE and -KO transgenic soybean seedlings. (A-C) represent the effects of different light intensities on the Fo, $\mathrm{Fv} / \mathrm{Fm}$, and NPQ of three types of soybean leaves. Vertical bars represent the SE $(n=3$; each treatment consisted of 30 seedlings).

The Chl fluorescence imager described the $C h l$ fluorescence parameters of the $\mathrm{T}_{2}$ and $\mathrm{T}_{3}$ generations of GmRIQ2-like-OE, -KO, and WT seedling leaves. The brightness of the NPQ image decreased significantly under strong light stress and the brightness change in the GmRIQ2-like-OE image was the most significant for both generations (Figures 9 and 10). 


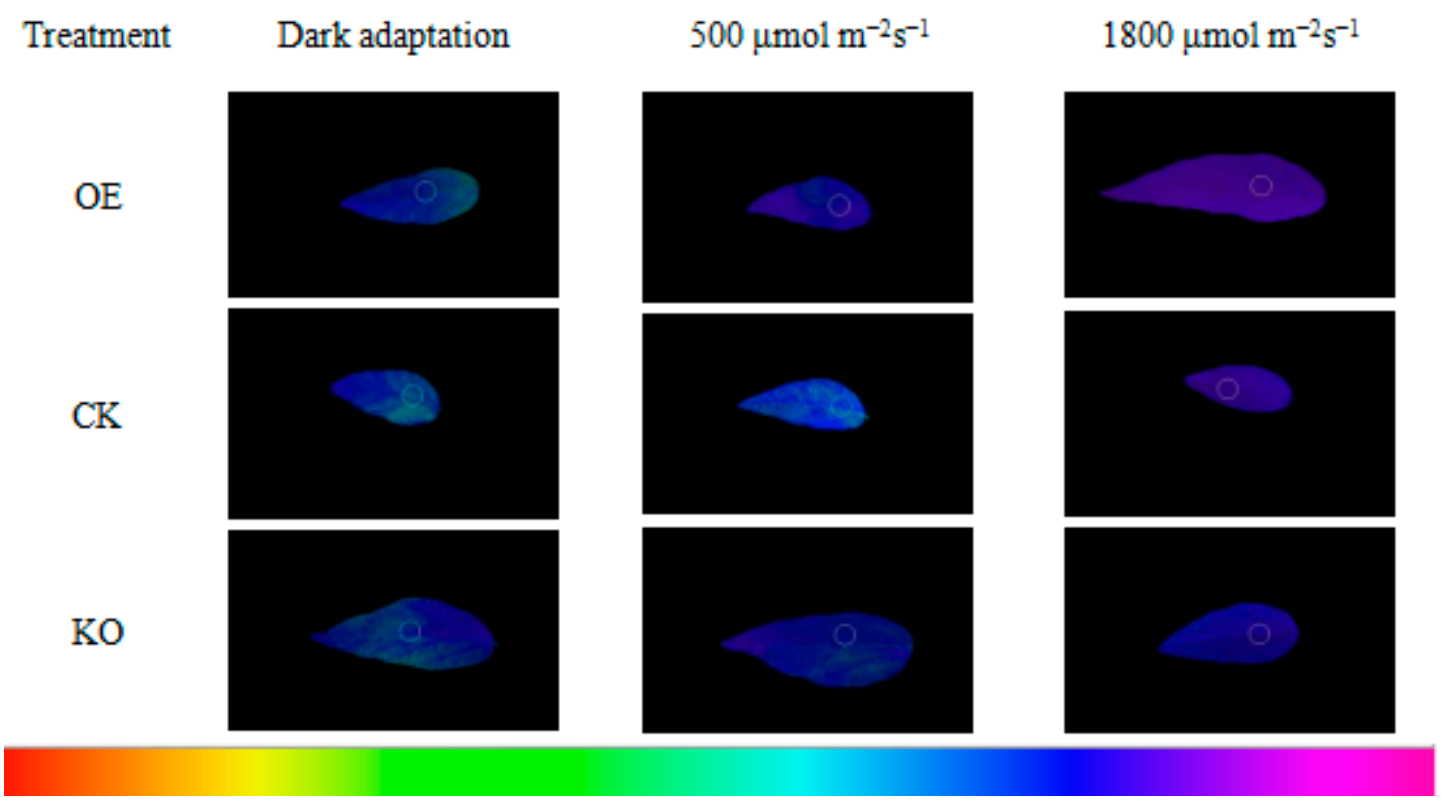

Figure 9. Effects of strong light stress on Chl fluorescence images of WT and the $\mathrm{T}_{2}$ generation of GmRIQ2-like-OE and -KO transgenic soybean seedlings.

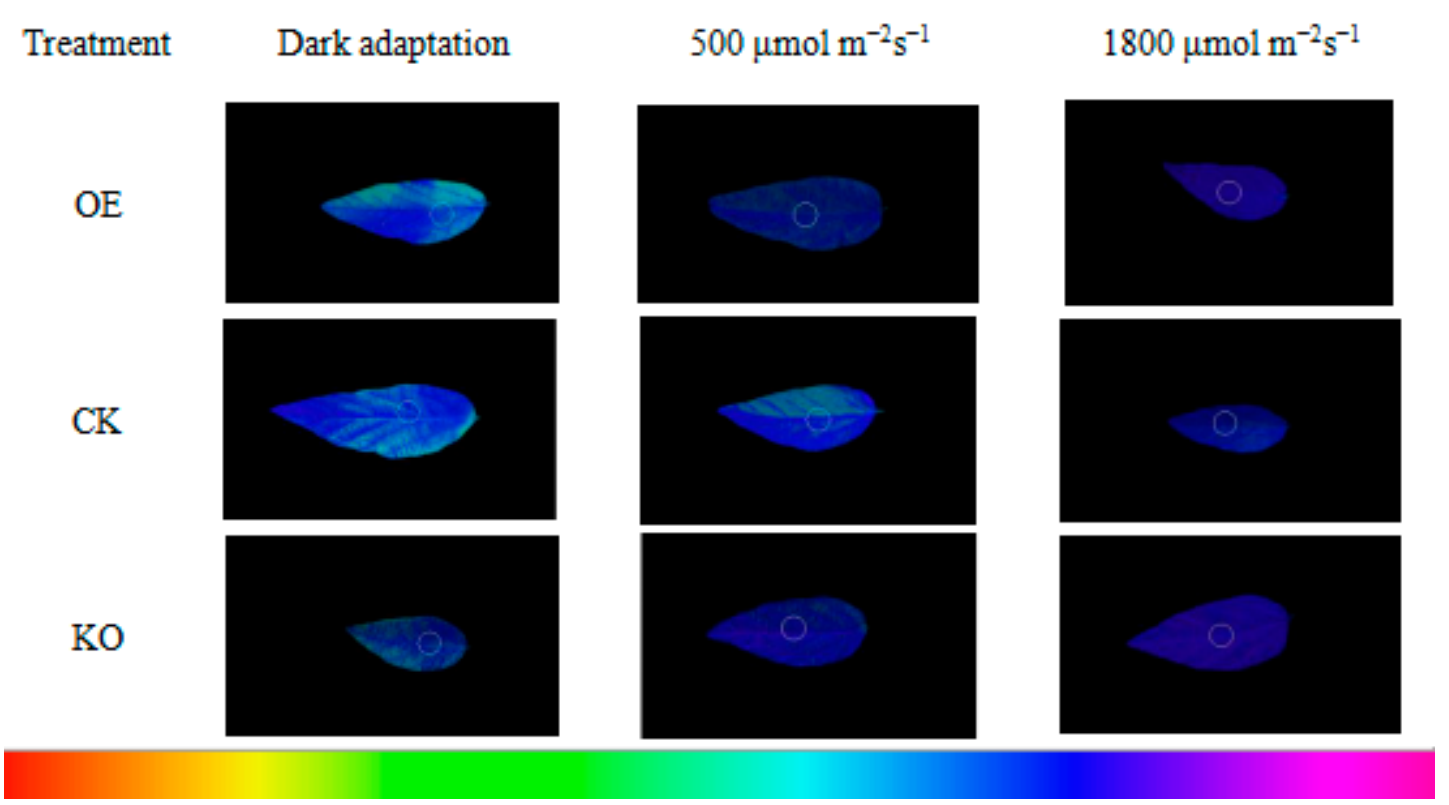

Figure 10. Effects of strong light stress on Chl fluorescence images of WT and the $\mathrm{T}_{3}$ generation of GmRIQ2-like-OE and -KO transgenic soybean seedlings.

\section{Discussion}

\subsection{Cloning and Functional Analysis of GmRIQ2-like}

Grana are stacked thylakoid membrane structures found in land plants that contain PS II and LHC IIs [65]. AtRIQ2 encodes uncharacterized grana thylakoid proteins, which are small proteins localized in the grana margin and stromal lamella [42]. Compared to the AtRIQ2 protein sequence, GmRIQ2-like was cloned successfully from the soybean cDNA library. Grana stacking is well-developed in land plants, and RIQ genes are highly conserved [66]. Therefore, the localization of GmRIQ2-like in this study was consistent with AtRIQ2. Based on the homology analysis, GmRIQ2-like was highly homologous with $P$. vulgaris L. In plants with artificially modulated LHC II levels, the degree of stacked grana 
depended on the LHC II levels [43,46]. RIQ proteins directly regulated the extent of grana stacking and LHC II organization around PS II, which was consistent with the phylogenic distribution of RIQ genes in phototrophs that develop the grana structure [42]. As a result, the RIQ proteins optimized LHC II organization, adjusted the photoprotective functions, and increased the sensitivity of LHC IIs to $\Delta \mathrm{pH}$ by optimizing the grana conditions [67]. Moreover, the activation of NPQ was dependent on the formation of proton gradients across thylakoid membranes (DpH) [68]. Thus, GmRIQ2-like clearly increased the NPQ of soybeans.

\subsection{Yield Variation between GmRIQ2-like-OE, -KO, and WT Soybean Seedlings}

Light is one of the key elements of photosynthesis that affects plant growth and development [7]. Under intense light stress, excess light significantly reduces the electron transport rate, the accumulation of reactive oxygen species seriously damages $\mathrm{RCs}$, and the photosynthetic activity and photochemistry efficiency are reduced, resulting in photoinhibition $[69,70]$. Therefore, it is necessary for plants to activate NPQ to dissipate excess light energy as heat. This phenomenon is widespread in plants and characterized by the reduction of photochemical efficiency, Fv/Fm, and photosynthetic carbon assimilation of PS II [16]. For example, Citrus unshiu leaves are affected by heat and strong light under sunny summer conditions. These stressors cause the stomatal closure of leaves, limit $\mathrm{CO}_{2}$ assimilation, result in excess energy, reduce electron transport chain continuity, and increase peroxide accumulation. [71]. In this study, the promoter element analysis indicated that GmRIQ2-like participated in photosynthesis and defense and stress responses of several abiotic stressors. Inferred from the results, as a gene that may advance NPQ, GmRIQ2-like protected soybean seedlings from strong light stress by dissipating excess activation energy as heat. Consistently, under the tested conditions, the agronomic trait results revealed that the photosynthetic products were yields of GmRIQ2-like-OE, -KO, and WT soybean seedlings, which were ranked as follows: GmRIQ2-like-KO > WT > GmRIQ2-like-OE. The results are not significantly different at the level of ${ }^{*} p<0.05$, but can reflect a certain trend.

\subsection{Energy Dissipating Ability Comparison between GmRIQ2-like-OE and WT Seedlings}

Previous studies demonstrated that greater reductions in the quantum efficiency of PS II photochemistry were attributed to increased energy dissipation [72]. Under strong light stress, substantial damages to photosynthetic pigments and decreased Chl contents were commonly observed phenomena [73,74]. Chl fluorescence is a useful, non-invasive tool used for the study of different aspects of photosynthesis, as well as for the detection of various environmental stressors in a wide range of plant species [75]. Moreover, SPAD values are positively correlated with Chl content [76]. In a previous study, Arabidopsis protected itself from short-term stress by increasing its NPQ level, which thereby dissipated light energy and decreased the efficiency of photochemical reactions in photosynthesis [77]. In this study, under the tested conditions, the SPAD values of GmRIQ2-like-OE seedlings were lower than WT. These results were consistent with the functions of GmRIQ2-like, which boosted energy dissipation and depressed Chl synthesis.

\subsection{Xanthophyll Cycle Pool Analysis of GmRIQ2-like-OE, -KO, and WT Soybean Seedlings}

The results indicated that zeaxanthin is important in the dissipation of excessive energy when plants are subjected to environmental stress factors in the presence of light [10]. Increased zeaxanthin contents or xanthophyll cycle pool sizes, which allow for the potential formation of zeaxanthin, were presumably related to a greater capacity to dissipate excess excitation energy as heat [10]. The xanthophyll cycle is involved in the conversion of violaxanthin to zeaxanthin via antheraxanthin by deoxycyclase [78]. In this study, under the tested conditions, zeaxanthin contents of GmRIQ2-like-OE soybean seedlings were greater than WT, and WT contents were greater than GmRIQ2-like-KO soybean seedlings. This finding was in accordance with the above results. A previous study found that the $n p q 2$ mutant blocked in the conversion of zeaxanthin to violaxanthin accumulates zeaxanthin and has a higher NPQ than WT cells [79]. In the presence of several abiotic stressors, sustained yield 
reductions were associated with both sustained increases in thermal energy dissipation (associated with zeaxanthin) and zeaxanthin contents [10]. Under water stress when watering was terminated, Nerium oleander leaves, which do not perform osmotic adjustment, exhibited sustained decreases in Chl fluorescence yields, indicating increased thermal energy dissipation and sustained increases of zeaxanthin levels [80]. Under heat stress, the rate of de-epoxidation of violaxanthin to zeaxanthin increased as leaf temperature increased, which is expected of an enzymatic reaction [81]. A similar temperature response was observed for the development of thermal energy dissipation based on the changes in Chl fluorescence yield of intact leaves [82]. Under cold stress in exposed field habitats, several evergreen species contained large zeaxanthin contents prior to sunrise during cold periods in the winter [83]. The retention of zeaxanthin was also accompanied by sustained reductions in photochemical efficiency [84].

In this study, the tissue culturing technique of soybean cotyledonary nodes was employed to obtain transgenic soybean seedlings. Additionally, the advanced CRISPR/cas9 gene KO technique was applied, which led to a high GmRIQ2-like silencing efficiency. Through various analyses of transgenic seedlings, which were used for determining photosynthesis and NPQ pathway products, results revealed that the main function of GmRIQ2-like was the enhancement of soybean NPQ to dissipate excess light energy and reduce or prevent plant photoinhibition in order to protect the plant. These findings will serve as a theoretical basis for the molecular breeding of soybean resistance, especially to strong light stress, and provide a foundation for cultivating a wide range of new soybean germplasms.

\section{Conclusions}

A soybean gene, GmRIQ2-like, was found to be highly homologous with AtRIQ2 in this study. GmRIQ2-like was localized in the grana and promoted NPQ. An assay of transgenic GmRIQ2-like-OE and -KO soybean seedlings revealed that GmRIQ2-like improved the photoinhibition sensitivity of plants to strong light by enhancing the dissipation of excess energy. Additionally, the agronomic traits and relative $\mathrm{Chl}$ and zeaxanthin contents also indicated that GmRIQ2-like resisted the degree of photoinhibition in soybeans. These results provide additional evidence that RIQ family genes function during photoinhibition and substantially increase our understanding of the molecular mechanisms of strong light tolerance. Moreover, these findings will serve as a reference for future studies on the responses of strong light-related pathways in soybeans and other crops.

Author Contributions: Conceptualization, B.Z.; methodology, H.Y., L.M. and J.Z.; software, J.Z.; validation, J.D.; formal analysis, D.L. and B.Z.; investigation, H.Y., L.M. and J.Z.; resources, B.Z.; data curation, J.D., D.L. and B.Z.; writing—original draft preparation, J.D.; writing—review and editing, J.D. and B.Z.; visualization, J.D., D.L. and B.Z.; supervision, D.L. and B.Z.; project administration, D.L.; funding acquisition, B.Z. All authors have read and agreed to the published version of the manuscript.

Funding: This research was funded by Breeding of New Soybean Varieties with Antireversing Genes No. 2016ZX08004002; Postdoctoral Scientific Research Developmental Fund of Heilongjiang Province, grant number No. LBH-Q18024 and "Cloning and preliminary function analysis of soybean GmRIQ2 gene" project, grant number No. SB17A02.

Conflicts of Interest: The authors declare no conflict of interest. The funders had no role in the design of the study; in the collection, analyses, or interpretation of data; in the writing of the manuscript, or in the decision to publish the results.

\section{References}

1. Duan, R.Y.; Wu, G.L.; Wang, Z.G. Effects of temperature stress on chlorophyll fluorescence parameters of strawberry. Chin. J. Spectrosc. Lab. 2011, 28, 2249-2252.

2. Qi, Y.J.; Yang, S.P.; Gai, J.Y. Genetic transformation and functional analysis of soybean GmFtsH gene. In Proceedings of the Abstract of the 23rd National Soybean Research and Production Symposium, Daqing, China, 24-26 August 2012.

3. Lou, Y.F. Study on Photoprotection and Related Gene Function of Phyllostachys Pubescens. Ph.D. Thesis, Chinese Academy of Forestry, Beijing, China, 2016. 
4. Jia, H.S.; Han, Y.Q. Progress in Photoinhibition of Photosynthesis in Higher Plants. Chin. J. Plant Sci. 2000, 17, 218-224. [CrossRef]

5. Zheng, B.; Gao, Z.M. A Preliminary Study on the Characteristics of NPQ and ETR at the Seedling Stage of Phyllostachys Pubescens. World Newsl. 2011, 1, 18-20.

6. Xu, D.Q. Photodamage Defense of Plant Photosynthetic Apparatus. Sci. Shanghai 2002, 54, 16-20.

7. Kangasjarvi, E.; Naveh, L.; Adam, Z. The thylakoid lumen protease Deg 1 is involved in the repair of photosystem II from photoinhibition in Arabidopsis. Plant Cell 2012, 19, 1039-1047.

8. Salgado-Luarte, C.; Gianoli, E. Herbivory may modify functional responses to shade in seedlings of a light-demanding tree species. Funct. Ecol. 2011, 25, 492-499. [CrossRef]

9. Zhou, L.Y.; Fu, Z.; Bu, Y. Research Progress of Plant Light Destruction Defense Mechanism. Subtrop. Plant Sci. 2016, 3. [CrossRef]

10. Demmig-adams, B.; Adams, W.W., III. Photoprotection and Other Responses of Plants to High Light Stress. Annu. Rev. Plant Physiol. Plant Mol. Biol. 1992, 43, 599-626. [CrossRef]

11. Guo, L.W.; Xu, D.Q. Light suppression of light and scorpion of coral tree leaves under natural conditions. J. Plant Physiol. 1994, 20, 46-54.

12. Lin, Z.F.; Peng, C.L.; Lin, Z.Q. Differences between 505nm and chlorophyll fluorescence in leaves induced by strong light. J. Trop. Subtrop. Bot. 1997, 3, 27-34.

13. Li, M.; Zhou, J.; Peng, C.L. Response of Overexpression of GLDH Arabidopsis Plants to High Light Stress. J. South China Norm. Univ. Nat. Sci. Ed. 2016, 48, 91-95. [CrossRef]

14. Tao, Z.Y.; Zou, Q. The Role of Mehler Reaction in Dissipating Excess Light Energy of Soybean Leaves. J. Plant Physiol. 2001, 1, 69-75.

15. Cheng, M.; Li, Z.Q.; Jiang, C.D.; Shi, L.; Tang, Y.D.; Zhang, J.Z. Photosynthetic Characteristics and Photodamage Defense Mechanism of Highland Barley. Acta Agron. Sin. 2008, 34, 1805-1811. [CrossRef]

16. Powles, S. Photoinhibition of photosynthesis induced by visible light. Annu. Rev. Plant Biol. 1984, 35, 14-44. [CrossRef]

17. Guo, L.W.; Xu, D.Q.; Shen, Y.G. The reason for the decline in photosynthetic efficiency of cotton leaves in the field at noon. J. Plant Physiol. 1994, 4, 360-366.

18. Xu, D.Q. Several Problems in the Study of Plant Light Stress. Plant Physiol. Commun. 2003, 5, $493-495$.

19. Zeng, J.Q.; Liu, H.X.; Wang, Y.R. Photoinhibition and restoration of cotyledons of cucumber seedlings at low temperature. Chin. J. Plant Physiol. 1997, 1, 15-20.

20. Bertamini, M.; Muthuchelian, K.; Rubinigg, M.M. Low-night temperature increased the photoinhibition of photosynthesis in grapevine (Vitis vinifera L. cv. Riesling) leaves. Environ. Exp. Bot. 2006, 57, 25-31. [CrossRef]

21. Murata, N.; Takahashi, S.; Nishiyama, Y. Photoinhibition of PhotosystemII under environmental stress. Biochim. Biophys. Acta 2007, 1767, 414-421. [CrossRef]

22. Donald, R.O. When there is too much light. Plant Physiol. 2001, 125, $29-32$.

23. Jiang, C.D.; Gao, H.Y.; Zou, Q. Iron deficiency increases the dissipation of excitation energy of soybean leaves. J. Plant Physiol. Mol. Biol. 2002, 28, 127-132.

24. Zhang, Y.R. Using Chlorophyll Fluorescence Technique to Reveal the Response of Artificially Cultivated Cucumber Seedlings to Stress Temperature, Light and Salinity; Ocean University of China: Qingdao, China, 2009.

25. Shi, S.B.; Li, T.C.; Li, M. Interactive effects of soil drought and glare on non-photochemical quenching of PSII reaction center in Kobresia humilis. Acta Physiol. Sin. Sin. 2015, 332, 155-163.

26. Mahajan, S.; Tuteja, N. Cold, salinity and drought stresses: An overview. Arch. Biochem. Biophys. 2005, 2, 139-158. [CrossRef] [PubMed]

27. Chen, Y.E.; Liu, W.J.; Su, Y.Q.; Cui, J.M.; Zhang, Z.W.; Yuan, M.; Zhang, H.Y.; Yuan, S. Different response of photosystem II to short and long term drought stress in Arabidopsis thaliana. Physiol Plantarum. 2016, 158, 225-235. [CrossRef] [PubMed]

28. Baroli, I.; Do, A.D.; Yamane, T.; Niyogi, K.K. Zeaxanthin accumulation in the absence of a functional xanthophyll cycle protects Chlamydomonas reinhardtii from photooxidative stress. Plant Cell 2003, 15, 992-1008. [CrossRef]

29. Yamamoto, H.Y.; Nakayama, T.O.M.; Chichester, C.O. Studies on the light and dark interconversions of leaf xanthophylls. Arch. Biochem. Biophys. 1962, 97, 168-173. [CrossRef] 
30. Stransky, H.; Hager, A. Das Carotenoidmuster und dieVerbreitung des lichtinduzierten Xanthophyllcyclus in versc-hiedenen Algenklassen. Arch. Mikrobiol. 1970, 73, 315-323. [CrossRef]

31. Niyogi, K.K. Photoprotection revisited: Genetic and molecular approaches. Annu. Rev. Plant Physiol. Plant Mol. Biol. 1999, 50, 333-359. [CrossRef]

32. Endo, T.; Uebayashi, N.; Ishida, S. Light energy allocation at PSII under field light conditions: How much energy is lost in NPQ-associated dissipation? Plant Physiol. Biochem. 2014, 81, 115-220. [CrossRef]

33. Walters, R.G. Towards an understanding of photosynthetic acclimation. J. Exp. Bot. 2005, 56, $435-447$. [CrossRef]

34. Pinheiro, C.; Chaves, M.M. Photosynthesis and drought: Can we make metabolic connections from available data? J. Exp. Bot. 2011, 62, 869-882. [CrossRef]

35. Jia, H.; Oguchi, R.; Hope, A.; Barber, J.; Chow, W. Differential effects of severe water stress on linear and cyclic electron fluxes through Photosystem I in spinach leaf discs in $\mathrm{CO}_{2}$-enriched air. Planta 2008, 228, 803-812. [CrossRef] [PubMed]

36. Zhang, J.L.; Meng, L.Z.; Cao, K.F. Sustained diurnal photosynthetic depression in uppermost-canopy leaves of four dipterocarp species in the rainy and dry seasons: Does photorespiration play a role in photoprotection? Tree Physiol. 2008, 29, 217-228. [CrossRef] [PubMed]

37. Smirnoff, N. The role of active oxygen in the response of plants to water deficit and desiccation. New Phytol. 2010, 125, 27-58. [CrossRef]

38. Wang, Y.Q. Response Mechanism of Photosynthetic Apparatus of Apple Peel under High Temperature and Strong Light Inhibition; Northwest A \& F University: Xi'an, China, 2015.

39. Xu, Z.F.; Luo, G.H. Effects of strong light and reactive oxygen species on photosynthesis of soybean. Chin. J. Bot. Engl. Ed. 1999, 8, 862-866.

40. Dietz, K.J.; Thomas, P. Novel regulations in photosynthetic redox control of plant metabolism and gene expression. Plant Physiol. 2011, 155, 1477-1485. [CrossRef]

41. Escalona, J.M.F.J.; Medrano, H. Water stress induces different levels of photosynthesis and electron transport rate regulation in grapevines. Plant Cell Environ. 1999, 22, 39-48.

42. Yokoyama, R.; Yamamoto, H.; Kondo, M.; Takeda, S.; Ifuku, K.; Fukao, Y.; Kamei, Y.; Nishimura, M.; Shikanai, T. Grana-localized Proteins, RIQ1 and RIQ2, Affect the Dynamics of Light-harvesting Complex II and Grana Stacking in Arabidopsis. Plant Cell 2016, 28, 2261-2275. [CrossRef]

43. Labate, M.T.; Ko, K.; Ko, Z.W.; Pinto, L.S.; Real, M.J.; Romano, M.R.; Barja, P.R.; Granell, A.; Friso, G.; Wijk, K. Constitutive expression of pea Lhcb 1-2 in tobacco affects plant development, morphology and photosynthetic capacity. Plant Mol. Biol. 2004, 55, 701-714. [CrossRef]

44. Kim, E.H.; Li, X.P.; Razeghifard, R.; Anderson, J.M.; Niyogi, K.K.; Pogson, B.J.; Chow, W.S. The multiple roles of light-harvesting chlorophyll a/b-protein complexes define structure and optimize function of Arabidopsis chloroplasts: A study using two chlorophyll b-less mutants. Biochim. Biophys. Acta Bioenerg. 2009, 1787, 973-984. [CrossRef]

45. Cui, Y.L.; Jia, Q.S.; Yin, Q.Q.; Lin, G.N.; Kong, M.M.; Yang, Z.N. The GDC1 Gene Encodes a Novel Ankyrin Domain-Containing Protein That Is Essential for Grana Formation in Arabidopsis. Plant Physiol. 2011, 155, 130-141. [CrossRef]

46. Pietrzykowska, M.; Suorsa, M.; Semchonok, D.A.; Tikkanen, M.; Boekema, E.J.; Aro, E.M.; Jansson, S. The light-harvesting chlorophyll a/b binding proteins Lhcb1 and Lhcb2 play complementary roles during state transitions in Arabidopsis. Plant Cell 2014, 26, 3646-3660. [CrossRef] [PubMed]

47. Caffarri, S.; Kouřil, R.; Kereïche, S.; Boekema, E.J.; Croce, R. Unctional architecture of higher plant photosystem II supercomplexes. EMBO J. 2009, 28, 3052-3063. [CrossRef] [PubMed]

48. Allahverdiyeva, Y.; Suorsa, M.; Rossi, F.; Pavesi, A.; Kater, M.M.; Antonacci, A.; Tadini, L.; Pribil, M.; Schneider, A.; Wanner, G. Arabidopsis plants lacking PsbQ and PsbR subunits of the oxygen-evolving complex show altered PSII super-complex organization and short-term adaptive mechanisms. Plant J. Cell Mol. Biol. 2013, 75, 671-684. [CrossRef] [PubMed]

49. Zhao, X.; Yang, H.W.; Liu, R.F. Responses of Heat Dissipation in Rice to Stress. Chin. J. Rice Sci. 2016, 4, 30.

50. Zhu, C.G.; Chen, Y.N.; Li, W.H.; Fu, A.H.; Yang, Y.H. Effect of Drought Stress on Photochemical Efficiency and Dissipation of Excited Energy in Photosystem II of Populus euphratica. Chin. Bull. Bot. 2011, 46, 413-424.

51. Zhao, X. Photosynthetic Response of Environmental Factors to Non-Photochemical Quenching of Rice Leaves; Huazhong Agricultural University: Wuhan, China, 2017. 
52. TAIR. Available online: https://www.arabidopsis.org/ (accessed on 3 April 2016).

53. Phytozome. Available online: https://phytozome.jgi.doe.gov/pz/portal.html (accessed on 3 April 2016).

54. ExPasy. Available online: http://web.expasy.org/translate/ (accessed on 3 April 2016).

55. TMHMM. Available online: http://www.cbs.dtu.dk/services/TMHMM/ (accessed on 3 April 2016).

56. MEGA5.0. Available online: http://bioinformatics.psb.ugent.be/webtools/plantcare/html/ (accessed on 3 April 2016).

57. NCBI Database. Available online: https://blast.ncbi.nlm.nih.gov/Blast.cgi?PROGRAM=blastp\&PAGE_ TYPE=BlastSearch\&LINK_LOC=blasthome (accessed on 3 April 2016).

58. CRISPRdirect. Available online: http://crispr.dbcls.jp/ (accessed on 5 April 2016).

59. Li, M.T.; Tan, W.Y.; Sun, M.Y.; Li, Y.G.; Li, W.B. Construction of TA Cloning Plant Expression Vector with Herbicide Resistance. Genom. Appl. Biol. 2015, 34, 2436-2440.

60. Yu, Y.Z.; Du, J.; Ji, J. Study on Freezing-thawing Method of Introducing Recombinant Plasmid into Agrobacterium tumefaciens. J. Jilin Agric. Univ. 2003, 3, 257-259.

61. Yoo, S.D.; Cho, Y.H.; Sheen, J. Arabidopsis mesophyll protoplasts: A versatile cell system for transient gene expression analysis. Nat. Protoc. 2007, 2, 1565-1572. [CrossRef]

62. Jia, Y.; Yao, X.; Zhao, M.; Zhao, Q.; Du, Y.; Yu, C.; Xie, F. Comparison of Soybean Transformation Efficiency and Plant Factors Affecting Transformation during the Agrobacterium Infection Process. Int. J. Mol. Sci. 2015, 16, 18522-18543. [CrossRef]

63. $\mathrm{Li}, \mathrm{J}$; S Song, Y.; $\mathrm{Wu}, \mathrm{K}$. Effects of $\mathrm{Cr}_{2} \mathrm{O}_{3}$ nanoparticles on the chlorophyll fluorescence and chloroplast ultrastructure of soybean (Glycine max). Environ. Sci. Pollut. Res. 2018, 3, 1-12. [CrossRef]

64. Hong, T.; Xu, D.Q. Non-photochemical quenching of chlorophyll fluorescence in coral and soybean leaves. Chin. J. Plant Physiol. 1999, 1, 15-21.

65. Dekker, J.P.; Boekema, E.J. Supramolecular organization of thylakoid membrane proteins in green plants. Biochim. Biophys. Acta (BBA) Bioenerg. 2005, 1706, 12-39. [CrossRef] [PubMed]

66. Mullineaux, C.W. Function and evolution of grana. Trends Plant Sci. 2005, 10, 521-525. [CrossRef] [PubMed]

67. Ruban, A.V.; Johnson, M.P.; Duffy, C.D. The photoprotective molecular switch in the photosystem II antenna. Biochim. Biophys. Acta. 2012, 1817, 167-181. [CrossRef]

68. Takahashi, S.; Milward, S.E.; Fan, D.Y.B.; Chow, W.S.; Badger, M.R. How does cyclic electron flow alleviate photoinhibition in Arabidopsis? Plant Physiol. 2009, 149, 1560-1567. [CrossRef]

69. Yamamoto, Y.; Aminaka, R.; Yoshioka, M.; Khatoon, M.; Komayama, K.; Takenaka, D.; Yamashita, A.; Nijo, N.; Inagawa, K.; Morit, N.; et al. Quality control of photosystem II: Impact of light and heat stresses. Photosynth Res. 2008, 98, 589-608. [CrossRef]

70. Flexas, J.; Diaz-Espejo, A.; Gago, J.; Gallé, A.; Galmés, J.; Gulías, J.; Medrano, H. Photosynthetic limitations in Mediterranean plants: A review. Environ. Exp. Bot. 2014, 103, 12-23. [CrossRef]

71. Hu, M.J.; Guo, Y.P.; Shen, Y.G. Environmental Regulation of Photosynthesis in Citrus. Chin. J. Appl. Ecol. 2006, 3, 181-186.

72. Moustakas, M.; Sperdouli, I.; Kouna, T.; Antonopoulou, C.I.; Therios, I. Exogenous proline induces soluble sugar accumulation and alleviates drought stress effects on photosystem II functioning of Arabidopsis thaliana leaves. Plant Growth Regul. 2011, 65, 315-325. [CrossRef]

73. Zhang, B.; Xiao, M.; Li, H.Y. The changes of hydrogen peroxide metabolism and related enzyme activities during the senescence of tobacco leaves caused by high light intensity. J. Anhui Agric. Univ. 2007, 34, 477-480.

74. Gong, D.H.; Wang, Z.Z.; Ji, X. Effects of low temperature and strong light stress on photosynthetic rate and photosynthetic pigment content of Algae sinensis. J. Inn. Mong. Agric. Univ. (Nat. Sci. Ed.) 2016, 6, 71-75.

75. Woo, N.S.; Badger, M.R.; Pogson, B.J. A rapid, non-invasive procedure for quantitative assessment of drought survival using chlorophyll fluorescence. Plant Methods. 2008, 4, 27. [CrossRef] [PubMed]

76. Wang, R.; Chen, Y.Z.; Chen, L.S.; Peng, S.F.; Wang, X.N.; Yang, X.H.; Ma, L. Correlation analysis of SPAD value and chlorophyII content in leaves of Camellia oleifera. J. Cent. South Univ. For. Technol. 2013, 33, 77-80.

77. German, T.C. The role of $\Delta \mathrm{pH}$-dependent dissipation of excitation energy in protecting photosystem II against light-induced damage in Arabidopsis thaliana. Plant Physiol. Biochem. 2002, 40, 41-49.

78. Yamamoto, H.Y.; Bugos, R.C.; Hieber, A.D. Biochemistry and Molecular Biology of the Xanthophyll Cycle; Oxford University Press: Oxford, UK, 1999. 
79. Govindjee, G.; Seufferheld, M. Non-photochemical quenching of chlorophyll a fluorescence: Early history and characterization of two xanthophyll-cycle mutants of Chlamydomonas reinhardtii. Funct. Plant Biol. 2002, 29, 1141-1155. [CrossRef]

80. Björkman, O. High-Irradiance Stress in Higher Plants and Interaction with other Stress Factors. In Progress in Photosynthesis Research; Springer: New York, NY, USA, 1987; pp. 11-18.

81. Bilger, W.; Bjorkman, O. Temperature dependence of violaxanthin de-epoxidation and non-photochemical fluorescence quenching in intact leaves of Gossypium hirsutum L. and Malva parvijora L. Planta 1991, 184, 226. [CrossRef]

82. Adams, W.W.; Demmig-Adams, B.; Winter, K. Relative contributions of zeaxanthin-related and zeaxanthin-unrelated types of 'high-energy-state' quenching of chlorophyII fluorescence in spinach leaves exposed to various environmental conditions. Plant Physiol. 1990, 92, 302-309. [CrossRef]

83. Oberhuber, W.; Bauer, H. Photoinhibition of photosynthesis under natural conditions in ivy (Hedera helix L.) growing in an understory of deciduous trees. Planta 1991, 185, 545-553. [CrossRef]

84. Schöner, S.; Krause, G.H. Protective systems against active oxygen species in spinach: Response to cold acclimation in excess light. Planta 1990, 180, 383-389. [CrossRef]

(C) 2020 by the authors. Licensee MDPI, Basel, Switzerland. This article is an open access article distributed under the terms and conditions of the Creative Commons Attribution (CC BY) license (http://creativecommons.org/licenses/by/4.0/). 